\title{
Comprehension of metaphors: A test of the two-stage processing model
}

\author{
RICHARD J. HARRIS \\ Kansas State University, Manhattan, Kansas 66506
}

\begin{abstract}
This study examined the hypothesis that metaphorical sentences are comprehended in a two-stage process of first understanding the literal meaning and then using that to construct the intended metaphorical meaning. Using metaphorical quotations from Shakespeare and nonmetaphorical equivalents, no differences between the two sentence types were obtained in a paraphrasing task which measured the subject's latency to initiate the paraphrase. Neither was there any metaphoricalnonmetaphorical difference in paraphrase adequacy. Only very minimal negative correlations of paraphrase adequacy and latency were obtained. Thus, no evidence for a two-stage processing model of metaphor comprehension was found. Reasons for such results were discussed, along with other possible processing models.
\end{abstract}

Most theories of language comprehension deal only with a single, literal level of meaning. Although such meaning is difficult enough to study, even the best such theory of comprehension could not account for an important aspect of language-metaphorical meaning. While metaphor is obviously an important aesthetic ingredient of literature (to suffer the slings and arrows of outrageous fortune), it is less obviously, but more importantly, a component of everyday language use, e.g., sports (The Royals massacred the Twins) and persuasive speaking (New York is on its fiscal knees begging for a life-saving injection of cash; $A$ cancer is growing around the Presidency). Such metaphors are readily comprehensible, but how such comprehension occurs has seldom been addressed in psycholinguistics.

One specific testable hypothesis about metaphor comprehension is that it occurs as a two-stage process of, first, understanding the words in a literal way and, next, using that literal meaning to construct the intended metaphorical interpretation. Evidence for such a two-stage comprehension process of other types of nonliteral language has been obtained studying conversationally conveyed requests (e.g., Can you color the circle blue? used as an imperative) by Clark and Lucy (1975) and unfamiliar proverbs (e.g., It's a silly fish that is caught twice with the same bait) by Brewer, Harris, and Brewer (Note 1). Both of these studies used reaction time to determine that subjects first comprehended the proverb or

This research was supported by Grant MH 28493-01 from NIMH and a grant from the Kansas State University Bureau of General Research. Preliminary results were presented at the Psychonomic Society meeting in Denver in November 1975. Appreciation is expressed to William Kempin and Judy Mathewson for data collection, Janet von Bevern for paraphrase ratings, Bill Hart and Cathy Haverfield for data analysis, and Gregory Monaco and Kristin Bruno for their helpful comments on the manuscript. Requests for reprints should be sent to Richard J. Harris, Department of Psychology, Anderson Hall, Kansas State University, Manhattan, Kansas 66506. conversationally conveyed request at its literal level and, if that was not appropriate in the given situation, next constructed the nonliteral interpretation. The present study tested this two-stage processing model with metaphors, using as the dependent variable the latency to initiate a paraphrase of a metaphorical or nonmetaphorical sentence. It was expected that, given equivalent length and comprehensibility, if the metaphors required an additional level of processing to comprehend, this fact should be reflected in longer latencies to initiate a paraphrase.

\section{METHOD}

The subjects were 28 native English-speaking undergraduate psychology students at Kansas State University who received extra course credit for participation. They were run individually. In addition, 72 other subjects from the same pool participated in two auxiliary rating tasks.

A total of 36 metaphorical quotations was selected from the following plays by William Shakespeare: Hamlet, Macbeth, Romeo and Juliet, Richard II, Henry IV: Part 1, Othello, Titus Andronicus, and The Merchant of Venice. Each sentence or phrase was readily, though not necessarily instantly, interpretable out of context to a modern listener and involved an interaction of semantic domains characteristic of metaphors, e.g., personification (The wind sits in the shoulder of your sail), concretion of an abstraction (Confused events new hatched to the woeful time), and man-object comparison ( $A$ son who is amongst a grove the very straightest plant). The Shakespearean materials were used in order to draw on a ready supply of good metaphors and to insure that the materials were difficult enough to maximize the possibility of observing any real difference in latency.

For each original metaphor $\left(\mathrm{M}_{\mathrm{o}}\right)$, three other sentences (or phrases) were written. A new metaphor $\left(M_{n}\right)$ had the same abstract meaning as the original metaphor $\left(\mathbf{M}_{\mathbf{o}}\right)$ but used a different literal semantic domain. Two nonmetaphorical sentences $\left(\mathrm{N}_{1}\right.$ and $\left.\mathrm{N}_{2}\right)$ expressed the same abstract meaning as the original metaphor but stated that meaning directly without the use of metaphor. All four sentences in any given sentence set contained exactly the same sentence structure and differed only in the number of content words (between one and four) necessary to express the metaphor. The four sentences in each set 
Table 1

Sample Sentence Sets

1. $M_{0}$ : Myself eating the bitter bread of banishment.*

$M_{n}$ : Myself tasting the acrid wine of banishment.

$\mathrm{N}_{1}$ : Myself sustaining the sorry state of banishment.

$\mathrm{N}_{2}$ : Myself enduring the cheerless plight of banishment.

2. $\mathrm{M}_{\mathrm{o}}$ : Your bait of falsehood takes this carp of truth.**

$M_{n}$ : Your seduction of falsehood takes this wench of truth.

$\mathrm{N}_{1}$ : Your offering of falsehood takes this gift of truth.

$\mathrm{N}_{2}$ : Your act of falsehood takes this result of truth.

3. $\mathbf{M}_{\mathrm{o}}$ : He hates the slime that sticks on filthy deeds. $\dagger$

$M_{n}$ : He hates the venom that oozes from poison deeds.

$\mathrm{N}_{1}$ : He hates the rancor that stays on cruel deeds.

$\mathrm{N}_{2}$ : He hates the malice that comes from dastardly deeds.

*Richard II, III, $1 \quad$ **Hamlet, II, $1 \quad$ †Othello, $V, 2$

were constructed to be as much alike as possible in abstract meaning, and all were in Shakespearean style but made sense in isolation. The mean lengths of the metaphorical and nonmetaphorical sentences were 9.21 and 9.15 words (39.61 and 41.82 letters), respectively. Three sample sentence sets appear in Table 1. The sentences were then rated by 28 new subjects for "metaphoricity," how metaphorical the sentence was on a scale from 1 (completely unmetaphorical) to 5 (highly and novelly metaphorical), and by 44 subjects for comprehensibility, also on a scale from 1 (very hard to understand) to 5 (easily understandable). Counterbalancing was such that all of the subjects on each rating task rated 36 sentences, exactly one from each sentence set, with the same number of $M_{0}, M_{n}, N_{1}$, and $N_{2}$ sentences, in a random but constant order for all subjects rating that list. The mean metaphoricity ratings for the $M_{0}, M_{n}, N_{1}$, and $N_{2}$ sentences were $3.56,3.49,2.61$, and 2.69 , respectively, while the mean comprehensibility ratings were $3.47,3.46,3.68$, and 3.51 , respectively. Thus, the metaphorical and nonmetaphorical items differed from each other in metaphoricity but not in comprehensibility.

Four lists of 36 sentences each were constructed. Each list contained one member from each of the 36 sentence sets, with nine each of $M_{0}, M_{n}, N_{1}$, and $N_{2}$. A given sentence occurred in one list in each of its four forms.

Four warm-up items occurred at the beginning of each list. These items were constant for all subjects and consisted of familiar quotations from Shakespeare which were not metaphorical (A horse, a horse, my kingdom for a horse; To be or not to be, that is the question). The subjects were read the following instructions: "This is a study of how well you understand writings of great literature. I am going to show you several quotations from the writings of William Shakespeare. You are to read each sentence and try to understand what it means. When you fully understand its meaning, I want you to paraphrase it, that is, tell what it means in your own words. This does not have to be a complete sentence or have perfect grammar; what is important is that you express the thought in the quotation in contemporary language that is clear and meaningful to you. Do not respond until you are sure you understand the whole sentence. If you are not completely sure what the sentence means or find one or more of the words unfamiliar, make the best guess you can for the paraphrase of the entire sentence. Avoid using the same literary style. Don't worry about the clock. The first couple of items will be for practice, to allow you to get used to the task. If you have questions during this time, you may ask them."

After four warm-up items, each subject received a list of 36 sentences in random order. Each was typed in large type (all capitals) on a $4 \times 6$ in. card. The subject sat just in front of the pile of cards. As he/she turned to a sentence, the experimenter started a stopwatch; at the subject's initiation of the paraphrase, the stopwatch was stopped and the latency recorded. Further pauses within the paraphrase were not recorded. The clock was not stopped if the subject's initial vocalization was clearly nonparaphrasirig (e.g., "uh ... uh," "Gee, this is a tough one"). The experimenter wrote down the paraphrase as the subject spoke and gave no feedback as to the correctness of the paraphrase. To avoid giving critical nonverbal cues, the experimenter sat at a 90-deg angle to the subject and never looked at him/her while the stopwatch was running. Each subject was allowed as long as necessary to to initiate his/her paraphrase.

At the end of the 36 experimental sentences, the subject was read the following instructions: "Many of the sentences contained metaphors, that is, figures of speech that talk about a person or object as if it were something that it is not; for example, clouds creeping across the sky talks as if clouds could walk or the man boiled talks about a man like a pot on the stove. On the paper I give you, I want you to write down anything you can remember about how you understood such sentences, what strategies you used to get at their real meaning, etc." The subject was then given as long as necessary to respond in writing to this question.

\section{RESULTS}

The mean latencies over all responses to metaphorical and nonmetaphorical sentences were $18.33 \mathrm{sec}$ and $18.86 \mathrm{sec}$, respectively. This difference was not significant $\left[F_{1}(1,27)=.302, F_{2}(1,35)=.041, \min F^{\prime}(1,44)=\right.$ $.036]$. Thus, there was no difference in time required to initiate paraphrases to metaphorical and nonmetaphorical sentences and no evidence for two-stage processing in the comprehension of metaphors.

All of the paraphrases were rated by an English major blind to experimental hypotheses and conditions. A 1-9 scale was used, with 1 indicating a very poor paraphrase and 9 a very good one. These mean paraphrase adequacy ratings were 6.56 and 7.02 for the metaphorical and nonmetaphorical materials, respectively. The mean ratings did not differ significantly for the two sentence types $[\mathrm{t}(1006)=.98, \mathrm{p}>.05]$. Pearson $\mathrm{r}$ correlations were figured between paraphrase adequacy and reaction time, with the resulting rs being -.008 and -.169 for metaphorical and nonmetaphorical items, respectively. Although the large number of data points makes the latter significantly different from zero $(z=3.85$ by Fisher's z-transformation test), there clearly is not a strong correlation of paraphrase latency and adequacy.

The subjects' introspections about how they had comprehended the metaphors were analyzed by content into five categories, with the number of responses in each indicated in parentheses: redefinition of some words in the sentence (18), relation to one's own experience (7), making sense of the sentence as a whole (6), understanding the symbolism or "hidden meaning" (3), and constructing a context or imagining an appropriate scenario (4). Three responses were not classifiable into any of the above categories, and several subjects mentioned more than one category. By far, the most frequent strategy mentioned was to redefine some words in the sentence. No one offered a verbal account of first comprehending a literal meaning of the sentence and 
then using it to construct a metaphorical meaning, although some did mention redefining some words and then putting these new definitions back together to form a whole idea. Although it is difficult to draw definitive conclusions from anecdotal data of this sort, the responses tend to suggest that whatever reinterpretation does occur comes at the level of certain words rather than as a meaning for the entire sentence.

\section{DISCUSSION}

No evidence for the two-stage model of comprehension was found, and, indeed, metaphors and nonmetaphors were not observed to involve any differences in processing. Why, then, might metaphors be processed differently than other nonliteral sorts of language, which have been shown to be processed via a two-stage model in the case of proverbs (Brewer, et al., Note 1) and conversationally conveyed requests (Clark \& Lucy, 1975)?

A metaphorical sentence is anomalous at the literal level and the metaphor itself may involve from one word to the entire sentence in varying degrees, whereas proverbs and conversationally conveyed requests have two nonanomalous and discrete meanings at the level of the whole sentence. For example, the metaphor I will speak daggers to her is anomalous taking a literal meaning of dagger, whereas the proverb Many little leaks sink $a$ ship is literally meaningful. To the extent that any possible two-stage processing model might operate in metaphor comparison, it would more likely be at the level of finding alternative readings for individual words (e.g., dagger) or phrases rather than for the whole sentence. The metaphorical meaning of the critical word(s) would then have to be integrated with the rest of the sentence to make a coherent whole. In the case of the proverb, however, the literal meaning of Many little leaks sink a ship would, as a unit, be used to construct the nonliteral meaning-which again would be a semantic whole, this time entirely figurative-in contrast to the metaphor's integration of a nonliteral meaning of one or two words into the meaning of the rest of the sentence.

Verbrugge (in press) argues on intuitive grounds against a two-stage model of metaphor comprehension, even one that would operate at the level of single words. Basically, he feels it erroneous to conclude that the most literal meaning is somehow the most basic and cognitively simplest, and that any nonliteral interpretation is necessarily more complex and only attainable through the use of some additional cognitive inferential processes. It may be that a metaphorical meaning is of ten easier to process in a given speech-act context or that, at the very least, its ease is highly context dependent in a way that a simple two-stage process could not handle. A two-stage model may implicitly assume that metaphor is a far more exceptional type of language than is in fact the case. The present results lend support to Verbrugge's (in press) claims.

A hypothesis not yet considered is that of a single stage of processing for both metaphorical and nonmetaphorical expressions, but with a longer, and presumably more complex, stage for the metaphors. If the metaphor-nonmetaphor latency difference had been significantly different in the predicted direction, such a hypothesis, in addition to the two-stage model, would be tenable. The failure to obtain such a difference, however, casts doubt on both hypotheses equally. It is also pos- sible to reject any interpretations based on differential sentence length or comprehensibility of the metaphorical and nonmetaphorical sentences.

How, then, are metaphors comprehended if the two-stage model is to be rejected? The complete answer to that question is not available at present, but some preliminary comments may be made. Verbrugge (in press) has suggested two protomodels of metaphor comprehension. The first is the juxtaposition hypothesis, whereby "events are elaborated separately and a relation found in one is sought in the other." He uses the analogy of placing two pictures side by side and scanning them for resemblances. This type of comprehension might most likely operate in similes, i.e., overt comparisons such as a snowflake is like an asterisk. It is also vaguely reminiscent of a feature-comparison model. Some even argue that most metaphors are interpretable as implicit comparisons (e.g., Kintsch, 1972, 1974).

The second approach suggested by Verbrugge (in press) is the fusion hypothesis, which involves "a transformation or warping of each [semantic] domain according to the particular constraints of the other." For example, for skyscrapers are the giraffes of a city, one might operate on the zoological and architectural semantic domains in parallel, perhaps visualizing a huge giraffe in the middle of a city skyline. Although such a process can lead to bizarre imagery and sometimes misleading interpretations, it may also be a highly efficient strategy for abstracting the metaphorical interpretation of an utterance.

It clearly is premature to expound a coherent and convincing model of how metaphors are comprehended; much work remains to be done. However, it appears that metaphors do not introduce considerable difficulty in comprehension in comparison to equivalent nonmetaphorical expressions. Metaphor is a common and useful facet of language that the neglect of its experimental study might tend to obscure. It is not a highly specialized form of language that becomes comprehensible only after the use of inferential processes operating on some literal or more basic meaning.

\section{REFERENCE NOTE}

1. Brewer, W. F., Harris, R. J., \& Brewer, E. F. Comprehension of literal and figurative meaning. Unpublished manuscript, 1974. (Available from W. F. Brewer, Department of Psychology, University of Illinois, Champaign, Illinois 61820).

\section{REFERENCES}

Clark, H. H., \& Lucy, P. Understanding what is meant from what is said: A study in conversationally conveyed requests. Journal of Verbal Learning and Verbal Behavior, 1975, 14, 56-72.

Kintsch, W. Notes on the structure of semantic memory. In E. Tulving and W. Donaldson (Eds.), Organization of memory. New York: Academic Press, 1972.

KintsCH, W. The representation of meaning in memory. Hillsdale, N.J: Erlbaum, 1974.

Verbrugge, R. R. Resemblances in language and perception. In R. Shaw and J. Bransford (Eds.), Perceiving, acting, and comprehending: Toward an ecological psychology. Hillsdale, N.J: Erlbaum, in press.

(Received for publication June 28, 1976.) 